records of any species being at once available at all times. I am able at a moment's notice to find any particular note that I have made during the past year on any one of the hundreds of species of insects studicd, whether yet determined or still without name, and anyone who familiarizes himself with the scheme as outlined can do the same. This is of course the test of any system of note keeping. Its proof is in its convenience and utility. I know of no other general record scheme that is at once so simple and so conveniently available at all stages of the work.

\title{
SOME WAYS OF REACHING THE PUBLIC
}

By H. A. Gossard

Last year I presented by title to the Association of Economic Entomologists a paper which has since been published in the Journar of Economic Entomology on "The Value and Makc-up of State and County Fair Exhibits." In this, I discussed one of the methods I use to acquaint the public with the entomological work of the Ohio Agricultural Experiment Station. This special feature of our work will, therefore, need no further mention in this paper. It is with the hope that a discussion of other methods of gaining publicity may bring to me some profitable suggestions from my fellow-workers and that I may impart a few to them that I offer this paper.

Of course, the main reliance of the official economic entomologist for publishing his results must be through the customary medium of publicity used by the institution with which he is connected. This is usually by means of the bulletin, circular and annual report. Professor Sanderson has given so good a discussion relating to "Publications of the Station Entomologist" in No. 4, Vol. 2 of the Journal of Economic Entomology that I shall pass over this subject quite briefly:

I wish, however, to emphasize the recommendation that such publications be generously illustrated. A carefully chosen, significant cut on the outside cover page of such a pamphlet secures for it a favorable impression before it is perused, and nearly always insures its being read. Abundant and good illustrations should also be scattered through the body of the pamphlet. The contents of the bulletin must, of course, depend upon the studies of the writer, but every entomologist has many lines of work open to him, and he should remember in making his selection that some of these will yield imme- diate and valuable results to his constitutents, while other questions equally easy to choose, and equally important, considered from the 
standpoint of the monetary values involved, may be far more baffling of solution, and may require long periods of observation and research to obtain any sort of satisfactory results-in fact, they may be incapable of satisfactory solution at all. No one thing has done more to strengthen the Entomological Department of the Ohio Station with its constituency than its work in spraying apples. The methods employed were largely transplanted from the states of the Far West, being chicfly adaptations of the methods first strongly emphasized by Dr. E. I). Ball, but these methods would not have been generally adopted or used to any considerable extent for a long time if the Experiment Station had not tested their value and adaptability to Ohio conditions. Because of his service to the state in thus giving a great impetus to the resurrection of the fruit-growing industry, the entomologist has gained such financial support that he has been enabled to direct the leisurely investigation of some of the more difficult and abstruse problems, the results of which, considered by themselves, would have brought him very meager support, comparatively speaking. It often happens that after years of faithful and conscientious work on an injurious insect, the investigator can do but little more than give a full account of its history, habits, instars, ctc., confessing that adequate remedial measures have not been found. While such work is valuable and must be done, the wise director of rescarch will so distribute his effort that part of it is likely to produce strikingly successful economic results, part of it will be given to important questions that do not seem to hold out any immediate promise of successful solution, and another part of it can be devoted to the strictly technical work which interests only the professional entomologist.

If the most promising fields of work are neglected, no amount of faithful plodding or persistence in trying to solve more difficult problems will secure for the Agricultural Experiment Station Department of Entomology the standing with its constituents that can be obtained from doing well some important piece of work that contributes directly and obviously to their pocket books. So far as the public is concerned, it does not matter so much whether the work is entirely new and original or whether it is largely demonstrational in character. Where demonstrational work is provided for through other agencies than the Experiment Station, more time is, of course, left to the station entomologists for original research, and it is desirable that a considerable part of their time be left for this purpose; but in my opinion there is always likely to be sufficient material for original observation in any large-scale demonstrational experiment to justify the required outlay of time and money to accomplish it, aside from considering the increased prestige gained for the department. 
This increased prestige often leads to such increased support that instead of being a handicap to research, as appeared probable when the work was commenced, it becomes a means of distinctly furthering original research. The chief point is that he who would go before the public with a message of any sort, whether it be original or merely demonstrational, must have a message that the people understand and which touches their welfare. They would far rather be taught how to utilize old knowledge that is of great value to them, than to be given tedious and unimportant information that is entirely new. The support they give will be proportional to the benefit which they think they have received. Demonstration meetings are very useful for arousing interest. A good discussion of the value of these is given by Prof. Franklin Sherman in No. 5, Vol. 2, of the Journal of Economic EnTomology. In Ohio we have made use of about the same methods as Professor Sherman in conducting spraying demonstrations. The railway companies are generally glad to distribute advertising matter along their lines and to put up posters in their depots throughout the territory that is likely to furnish excursionists to the demonstration orchards. Considerably more important than spraying demonstrations have been our ficld meetings to study results of the season's work. The first of these was held in the Schmitkons orchard in the fall of 1907 . The results of spraying in this orchard are set forth in Bulletin 191 of the Ohio Station. Besides a detailed explanation of how the spraying had been done on the different plots, illustrated by a spraying outfit in action, water being used for the liquid, a diversified program was prepared covering several phases of orcharding. The station horticulturist was present and gave a lecture on pruning and culture of the orchard, the station botanist gave a lecture on orchard diseases, and a practical orchardist gave an address on marketing and packing.

All of the arrangements were made by the State Horticultural Society, and so successful was the meeting that it was decided to have an annual field meeting of the society each fall at some place where practical lessons could be learned. The same general plan in regard to program has been followed at subsequent meetings and while these have not always been held in orchards that were in charge of the Entomological Department, entomological topics have always had a place on the program. They have generally been held in an orchard which was for the season in charge of some one of the station departments, but in some cases have been taken to the orchard of some expert fruit-grower who was able to teach valuable lessons from his orchards and his fruit-growing methods. The present autumn, the field meeting was held at the Station orchards at Wooster. These 
were all used during the season by the Department of Entomology for spraying experiments in which the effects of the different combinations of sprays such as lime-sulfur and arsenate of lead, and bordeaux mixture and arsenate of lead in different proportions were shown on foliage and fruit. At an earlier date, about midsummer, all the farmers' institute speakers employed by the state assembled in a convention were conducted through the same orchards and explanations were given of the work being done and the treatment that had been given to the different plots. The reports. of these autumn field meetings of the Ohio Horticultural Society have been printed and distributed as circulars of the Ohio Station. A good idea of what is done at these field meetings and the nature of the papers or off-hand talks presented, can be obtained by consulting Circulars 87 and 103 which contain quite full details.

The farmers' institute also furnishes a method for reaching a good many people. It often happens that a man will read with interest a bulletin, the author of which is personally known to him, when it would hardly be noticed if the writer were a stranger. There is a limit, however, to the amount of institute work that can be done by the research student, and it is generally necessary to discourage calls of this kind rather than try to multiply them. At the Ohio Station we print a folder each fall which contains the following introductory paragraph:

The members of the Station Staff named below are prepared to assist at a limited number of independent farmers' institutes and similar meetings. No per diem is charged for this service, but it is expected that the speakers will be reimbursed for their necessary traveling and hotel expenses.

Where two or more names are given at the head of a list of topics requests may be made for discussion of any of the topics on the list by any member of the department. The lecturer requested will be sent if possible, but if conflicting engagements make this impossible, some other person qualified to discuss the subject will be sent.

At the head of the list of entomological topics we print the names of the entire entomological staff as far as they are available for such work, thus:

H. A. Gossard.

\section{DEPARTMENT OF ENTOMOLOGY}

W. H. Goodwin.

R. D. Whitmarsh.

1. How to spray the apple orchard. (In some of our experiments the net returns have averaged $\$ 400$ and $\$ 500$ per acre for a single crop.)

2. How to spray peach, pear and plum orchards.

3. How to treat the vineyard to prevent Grapeberry worm and other insect enemirs of the grape.

4. Home-made sprays, commercial insecticides and spraying machinery.

5. Our allies in the war against insects; birds, insectivorous animals, parasites, fungous and bacterial diseases. 
6. Inscets injurious to stored grain and how to prevent injury.

7. Insects injurious to cereal grains.

8. Insccts injurious to forage crops.

9. Insects injurious to garden crops.

10. Insects injurious to potatoes.

11. Insects injurious to shade and ornamental trees.

12. Insects injurious to livestock.

13. How to treat San José scale.

14. How to treat the Fruit Bark Beetle and other borers.

15. Wonders of the Insect World (40 minutes night stereopticon lecture, many slides in natural color.)

16. Some birds and small animals, good and bad; their habits and value (40 minutes, night stereopticon lecture, several colored slides.)

17. Relation of insects to human welfare (40 minutes, night, by H. A. Gossard.)

18. Spraying machinery ( 40 minutes night stereopticon lecture, by W. H. Goodwin.

19. Any entomological topic not listed will be discussed if request for the same is made two weeks before the institute.

In our experience, simple talking without any illustrative material is not satisfactory. We have several ways for illustrating our lectures. For day lectures we make much use of enlarged bromide pictures. Iife histories of insects, character of damage wrought by them, comparative results of treatment, different types of insecticidal machinery, etc., are quite susceptible to this kind of illustration. We use pasteboard mounting cards about $20 \times 24$ inches, or larger, so they easily take plates $16 \times 20$. These will carry illustrations sufficiently large to be seen readily by all the members of an average institute audience of 100 to 500 people. To economize weight we sometimes put a plate on each-side of the board and sometimes we mount the plates on sheets of cloth instead of board. To carry these illustrations we wrap them in a cover of oilcloth and put a shawl strap about them. The lithographic chart recently prepared by Prof. F. L. Washburn of Minnesota for use in the schools of his state seemed so well adapted for institute work that I have had this backed with cloth and expect to make more or less use of it in giving the introductory lecture at institutes. Our Ohio institutes are usually for two days, and each worker is generally expected to give four and sometimes as many as six lectures during the session. For evening lectures we make much use of the stereopticon. The Bausch and Lomb Optical Co. have built a portable lantern according to specifications furnished them by our Messrs. Houser and Goodwin which can be mounted on an ordinary camera tripod and the entire machine with accessories, excepting the slides, can be packed in an ordinary suit case and weigh, when packed, but little more than thirty pounds.

We use an alco-lite attachment with this machine and find it quite satisfactory. We have also an electric lantern which we use in build- 
ings that are wired and supplied with electricity and where exceptionally large audiences are expected, but this machine is altogether too heavy for general use. We have several hundred lantern slides, three or four hundred having been chosen from the Slingerland list and we have made about as many of our own. We have just as many as possible of these in natural colors and arrange them so as to give a connected and logical lecture. The first slide is generally the one which shows the division of insects into two groups, those with sucking and those with biting mouth-parts, then a series illustrating complete and incomplete metamorphosis is shown, then slides illustrating fecundity, parasitism, predaceous forms, the work of bacterial and entomophilus diseases, the functions of birds and insectivorous animals, mimicry, etc. After this introductory matter, special consideration is given to such insects as are apt to be of most local interest or which illustrate the day lectures. Some of the finest, most beautiful, and surprising slides are always reserved for the close of the lecture. Topic 16 has been added to give a wider range of choice and to accommodate audiences which in preceding seasons have heard No. 15. Mr. Slingerland has prepared many of the bird slides for us and we have made a good many ourselves. Besides birds, the rabbit, the rat, the skunk, the mole, the shrew, the woodchuck and the toad are considered. The natural history of these is discussed in more or less detail and suggestions for control or propagation are furnished. Many insect slides are worked into this lecture to illustrate the food habits of birds. Topic No. 17 is the article published in No. 5, Vol. 2, Journal of Economic Entomology. This is a somewhat heavy lecture for the average audience and though generally well received, I doubt if it leaves so lasting an impression as the stereopticon lectures and I know it is not so popular. The evening lecture by $\mathrm{Mr}$. Goodwin on "Spraying Machinery" is very practical and is generously illustrated with a splendid set of slides of our own making, but we have not yet had time to determine whether or not there will be much call'for it. The county schools of agriculture lasting from one to two weeks each, also offer an opportunity for giving short courses in entomology, and will, doubtless, supplant the farmers' institutes in time. These are comparatively new developments in Ohio agricultural education, and we have thus far had little opportunity to test their possibilities for entomological instruction. The horticultural and agricultural train offer some opportunities for scattering information, but thus far, we have not tried to utilize this method of propaganda. I belicve Mr. Shaw of our state department of Agriculture and the Department of Agricultural Extention at our state university have used it with considerable success. 
The midwinter Ohio Apple Show at Columbus, held in conjunction with the annual meeting of the State Horticultural Society, affords an opportunity of which we are glad to avail ourselves to exhibit our spraying results to the public. We purchase whatever apples are necessary from the orchardists, with whom we coöperate, to show the results of spraying upon insects, the effects of different sprays in causing russeting, etc. Our State Horticultural Society always expects a report from the station entomologist, and from the state inspector of nurseries and orchards as well, upon the observations and results of the year's work.

The agricultural newspaper furnishes an easy means for exploiting station work, but $I$ am obliged to confess that I have utilized it far less than I should have done for this purpose. While I have occasionally volunteered an article for the Ohio Farmer and for other agricultural papers printed in the state, I have, for the most part, confined myself to answering such questions as were submitted to me by the editors with the request that I answer them. As between too much or too little publicity through newspaper writing, I believe too little is preferable, but am satisfied that I would help more people if I contributed at least one good practical article each month. One disadvantage about too much publicity, especially of the kind gained through newspaper writing, is that departmental correspondence is apt to become too burdensome and encroach too much upon the time of the staff. We are now obliged to anwer from 5,000 to 7,000 entomological queries per year at the Ohio Station and we almost wish it were unnecessary to ever increase the number. I am now asking the Legislature for the means to hire, a clerk who can be trained to answer a large fraction of these without consulting the entomologists except to make certain the identification of insects. To enable him to do this the more readily, we expect to prepare short printed accounts of the life histories and habits of the more important economic insects with recommendations for treatment against the same. I am satisfied that this will be more satisfactory to all parties than our present method and at the same time, cheaper than sending out a bulletin or circular in answer to each inquiry. In whatever way such inquiries are answered, cnough of detail must be given to enable the inquirer to obtain a complete answer to all the questions he had asked and besides these, to all that he ought to have asked. If this care is taken to inform inquirers, the correspondence of the entomologist will increase fully as fast as is desirable, and I sometimes think faster. I keep small slips just large enough to fit into our letter envelopes, having printed directions on each for making one of the various sprays, for using poisoned bait for cutworms, for treating cabbage worms, for 
combating the striped cucumber beetle, etc.; others giving the addresses of manufacturers of spraying machinery and of insecticides. and such other information as is most frequently asked for. This saves much time in dictating letters and an extension of the plan would enable a bright clerk to take care of much of the correspondence without much help.

The time has long since gone by when the station entomologist can quietly remain at his office headquarters and prosccute his researches without interruption by his constitutents. Today they wish to know what he has done and what he is doing and it is apt to be his own fault if they do not value his advice as highly as they do that of other agricultural experts in different fields of endeavor. Upon his good sense and cleverness in presenting results that are worth presenting, will depend the continuance of the public favor toward entomological activities, now so happily achieved and held.

\section{SPRAYING FOR THE EUONYMUS SCALE}

By Z. P. MercatF, Assistant Entomologist, State Department of Agriculture, Raleigh, N.C.

The euonymus is one of the most desirable hedge plants grown in North Carolina. It is evergreen, hardy, and with the exception of the euonymus scale seems to be free from diseases. This insect, however, is so destructive that what were once beautiful hedges are now reduced to scraggly clumps or the entire hedge has been cut down and removed.

During the summer of 1909 , what had once been a magnificent hedge was turned over to us for experimental purposes. This hedge consisted of about one thousand feet averaging four and one-half feet high, and about two feet wide. This together with ten large clumps averaging thirty feet in diameter and twenty to twenty-five feet in height gave us an excellent chance to try out practical remedies. The hedge was in varying degrees of infestation. In fact, about three hundred feet of the hedge was so far gone that it was thought best to cut it down and reset with young hedge. About 90 per cent of the plants in the portion removed were dead, the remainder were very nearly dead. On July 16, 1909, kerosene emulsion, prepared in the usual manner, at the strengths of 15, 20 and 30 per cent oil was used on three different clumps of euonymus separate from the main hedge. All three clumps were badly infested. These clumps were inspected on July 23. At this time it was found that the 15 per cent kerosene emulsion had done very little good,-certainly not more than 10 per 